\title{
PR-22. PYRANOPYRAZOLES AS EFFICIENT ANTIMICROBIAL AGENTS: GREEN, ONE POT AND MULTICOMPONENT APPROACH
}

\author{
$\underline{\text { G. M. Reddy }}^{1,2}$, J.R. Garcia ${ }^{2}$, G. V. Zyryanov ${ }^{1,3}$ \\ ${ }^{1}$ Ural Federal University of the first President of Russia B. N. Yeltsin, \\ Mira St., 19, Yekaterinburg, 620002, Russia \\ ${ }^{2}$ Department of Chemistry of the State University of Ponta Grossa, \\ Av. Gal. Carlos Cavalcanti, 4748 - Uvaranas, Ponta Grossa - PR, Brazil, 84030-900 \\ ${ }^{3}$ I. Ya. Postovsky Institute of Organic Synthesis UB RAS, \\ S. Kovalevskoy/Akademicheskaya St., 20/22, Yekaterinburg, 620990, Russia \\ E-mail: drreddy.organic@gmail.com
}

Innovative therapeutic heterocycles having precisely thiadiazolyl-pyranopyrazole fragments were prepared by using the ecofriendly synthetic route. Entire compounds formed in quantitative yields. All the composites tested for their antimicrobial effectiveness against four microbial, two beneficial fungi's and accurately measured the minimum inhibitory concentrations (MIC and MBC/MFC), along with some initial structure activity relationships (SARs) also discussed $[1,2]$. From the biological outcomes. The possible presence of a nitro substituent on this composite may undoubtedly enhance the activity. All things considered and suggested that this outstanding green synthetic approach is used to develop biological active compounds. On top of that, biological results confirmed that these biologically energetic motifs suitable for additional preclinical examine with the aim of standing novel innovative drugs [3].
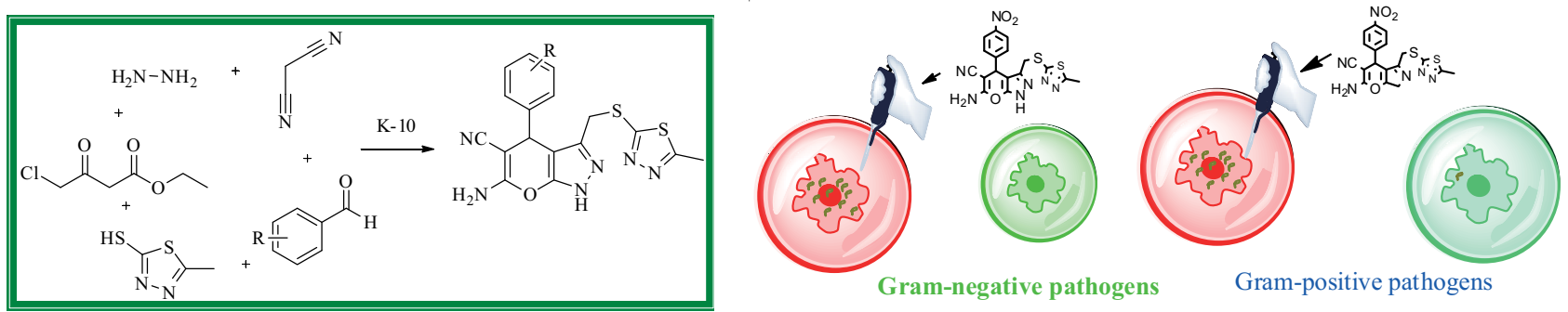

1. Outstanding antimicrobial activity

2. Gram-negative pathogens effected more

3. Substituted group may influence

4. Green synthesis

anantitativa viald

\section{References}

1. Synthesis, antimicrobial activity and advances in structure-activity relationships (SARs) of novel trisubstituted thiazole derivatives / G. M. Reddy [et al.] // Eur. J. Med. Chem. Elsevier Masson. 2016. Vol. 123. P. 508-513.

2. Pyranopyrazoles as efficient antimicrobial agents: Green, one pot and multicomponent approach / G. M. Reddy [et al.] // Bioorg. Chem. Academic Press. 2019. Vol. 82. P. 324-331.

3. An efficient and green approach: One pot, multi component, reusable catalyzed synthesis of pyranopyrazoles and investigation of biological assays / G. M. Reddy [et al.] // J. Saudi Chem. Soc. Elsevier. 2018. In press. 